\title{
Effect of Hot Deformation and Controlled Cooling Process on Microstructures of Ti-Zr Deoxidized Low Carbon Steel
}

\author{
Chao WANG, Zhaodong WANG* and Guodong WANG \\ The State Key Laboratory of Rolling and Automation, Northeastern University, Shenyang, 110819 China. \\ (Received on February 22, 2016; accepted on June 9, 2016)
}

\begin{abstract}
It has been known that microstructures in steel welding heat affected zones can be improved by inclusion-induced intragranular ferrite nucleation. In this paper, the influence of inclusions on microstructure in steel base metal under thermo-mechanical conditions was further researched. Hot deformation and controlled cooling process were simulated with $\mathrm{Ti}-\mathrm{Zr}$ deoxidized low carbon steels. Microstructural characteristics and transformation behaviors were analyzed. Results showed that inclusions were mainly (Ti, $\mathrm{Zr}$ )-rich oxide with $\mathrm{MnS}$ precipitation on the surface and they were effective for acicular ferrite nucleation in the coarse-grained heat affected zone. Acicular ferrite could still form in hot deformed and recrystallized austenite grains, but its volume fraction reduced with the decrease in deformation temperature. Accelerated cooling above $600^{\circ} \mathrm{C}$ and addition of boron significantly promoted acicular ferrite structure and the hardness value also increased. Hot rolling simulation indicated that for the experimental Ti-Zr-B steel, microstructure could not be further improved by applying conventional controlled rolling deformation. Instead, fine-grained acicular ferrite structure and high hardness value were obtained through high temperature deformation and controlled cooling process, during which (Ti, Zr)-oxide inclusions contributed to the intragranular acicular ferrite formation.
\end{abstract}

KEY WORDS: Iow carbon steel; Ti-Zr deoxidization; hot deformation; controlled cooling; acicular ferrite.

\section{Introduction}

Inclusion-induced acicular ferrite (AF) is a preferred microstructure in high-strength low-alloy (HSLA) steels weld metal and heat affected zone (HAZ) by virtue of its relatively high strength and toughness. ${ }^{1,2}$ During the large heat input welding thermal cycle, austenite grains in the coarse-grained HAZ (CGHAZ) grow into a large size and tend to form coarse bainite or Widmanstätten ferrite plates sheaves which deteriorate the toughness severely. Instead of these coarse structures, acicular ferrite could nucleate intragranularly and form a refined microstructure of interlocking configuration provided that effective intragranular nucleation sites exist in steel. Among the non-metallic inclusions employed for this purpose, $\mathrm{Ti}_{2} \mathrm{O}_{3}$ has been confirmed being very effective for acicular ferrite nucleation. The particular inclusions in wrought steels could be introduced in the melt deoxidization process. The steels are generally subjected to controlled rolling and controlled cooling process, where the particular inclusions act as inert impurities. The grain refining effects take place only when the steels are used for welding process. Researches on microstructure improvement by residual oxide inclusions in hot-deformed steels have been done. ${ }^{3-6)}$ However, evaluation of effect of inclusions on microstructure in steel base metal during the hot rolling and cooling process is relatively insufficient.

\footnotetext{
* Corresponding author: E-mail: wangzdneu@sina.com

DOI: http://dx.doi.org/10.2355/isijinternational.ISIJINT-2016-106
}

The particle-stimulated nucleation tends to take place in large-sized austenite grains. This advantage provides grain refinement opportunities for heavy steel or long products that are not proper for performing thermo-mechanical controlled process (TMCP). For hot-rolled HSLA steel plates, the possibility and degree of as-rolled microstructure refinement by the aid of oxide inclusions are not known clearly. With this purpose, in this paper, we have studied the influence of inclusions on microstructure in steel base metal under thermo-mechanical conditions. Hot deformation and controlled cooling process were simulated with $\mathrm{Ti}-\mathrm{Zr}$ killed low carbon steels. Microstructural characteristics and transformation behaviors were analyzed.

\section{Experimental}

Chemical compositions of experimental steels are shown in Table 1. The steels were melted in a laboratory $50 \mathrm{~kg}$ vacuum induction furnace and cast into ingots in a $20 \mathrm{kPa}$ argon atmosphere. Steels TZ and TZB were both killed

Table 1. Chemical compositions of the experimental steels in wt.\%.

\begin{tabular}{ccccccccc}
\hline Steel & $\mathrm{C}$ & $\mathrm{Si}$ & $\mathrm{Mn}$ & $\mathrm{Al}$ & $\mathrm{Ti}+\mathrm{Zr}$ & $\mathrm{B}$ & $\mathrm{N}$ & $\mathrm{O}$ \\
\hline $\mathrm{TZ}$ & 0.08 & 0.11 & 1.65 & - & 0.01 & - & 0.002 & 0.003 \\
$\mathrm{TZB}$ & 0.07 & 0.12 & 1.67 & - & 0.01 & 0.001 & 0.002 & 0.003 \\
$\mathrm{~A}$ & 0.08 & 0.12 & 1.65 & 0.035 & - & - & 0.002 & 0.002 \\
\hline
\end{tabular}


with $\mathrm{Ti}$ and $\mathrm{Zr}$. Boron was added in steel TZB to increase the hardenability. Steel A was killed with $\mathrm{Al}$ and was used for comparison. The ingots were hot-rolled into plates of 12 $\mathrm{mm}$ thickness. The as-hot rolled steel plates were used for welding HAZ simulation and thermo-mechanical treatment experiments.

Ti deoxidization in steel is generally aimed at improving HAZ toughness for high heat input welding. ${ }^{78}$ ) Firstly in this research, the effectiveness of inclusions in $\mathrm{Ti}-\mathrm{Zr}$ killed steel for CGHAZ microstructure refinement was evaluated by HAZ simulation experiments using a thermo-mechanical simulator of the type MMS300 developed by Northeastern University of China. Specimens with dimensions of $11 \mathrm{~mm} \times$ $11 \mathrm{~mm} \times 55 \mathrm{~mm}$ were machined from as-rolled TZ and A steel plates. The simulated welding heat input was $200 \mathrm{~kJ} /$ $\mathrm{cm}$. Samples were heated at a rate of $100^{\circ} \mathrm{C} / \mathrm{s}$ to $1400^{\circ} \mathrm{C}$ and held for $3 \mathrm{~s}$. The cooling time from $800^{\circ} \mathrm{C}$ to $500^{\circ} \mathrm{C}$ $\left(t_{8 / 5}\right)$ was $215 \mathrm{~s}$. The samples were then machined to 10 $\mathrm{mm} \times 10 \mathrm{~mm} \times 55 \mathrm{~mm}$ for Charpy V-notch impact test at $-20^{\circ} \mathrm{C}$. The CGHAZ microstructures were observed. The inclusion compositions were analyzed by electron probe microanalyzer (EPMA).

Influences of hot deformation and cooling process on microstructures were studied through simulated thermomechanical treatment using MMS300 simulator. Cylindrical specimens of $8 \mathrm{~mm}$ diameter and $15 \mathrm{~mm}$ length for simulation experiments were machined from as-rolled steel plates. The TZB steel was selected for studying the influence of hot deformation temperatures. The samples were heated at $10^{\circ} \mathrm{C} / \mathrm{s}$ to austenitizing temperature of $1250^{\circ} \mathrm{C}$ with $5 \mathrm{~min}$ holding, and then cooled at $2^{\circ} \mathrm{C} / \mathrm{s}$ to deformation temperatures of $1150-850^{\circ} \mathrm{C}$. $50 \%$ uniaxial compression was loaded at a strain rate of $5 \mathrm{~s}^{-1}$ followed by continuous cooling at $2{ }^{\circ} \mathrm{C} / \mathrm{s}$ to room temperature. The as-transformed microstructures were observed. Effect of cooling process was studied by varying accelerated cooling rate and cooling stop temperature, as shown in Fig. 1(a), which are two key parameters for steel plate production. Before accelerated cooling, 50\% uniaxial deformation was applied at $1050^{\circ} \mathrm{C}$ followed by cooling at $1.5^{\circ} \mathrm{C} / \mathrm{s}$ to $1030^{\circ} \mathrm{C}$. After accelerated cooling, the samples were cooled at $0.5^{\circ} \mathrm{C} / \mathrm{s}$ to room temperature. Cooling stop temperatures of $660-510^{\circ} \mathrm{C}$ at a rate of $20^{\circ} \mathrm{C} / \mathrm{s}$, and cooling rates of $1.5-20^{\circ} \mathrm{C} / \mathrm{s}$ with stop temperature of $600^{\circ} \mathrm{C}$ were selected respectively.

Thermo-mechanical treatment simulating hot rolling of steel was also conducted by using MMS300 simulator, as illustrated in Fig. 1(b). Two different deformation processes were carried out, i.e. one-stage deformation and two-stage deformation, to simulate high temperature rolling and conventional controlled rolling, respectively. In one-stage deformation, the cylindrical sample was $50 \%$ uniaxially compressed at a strain rate of $5 \mathrm{~s}^{-1}$ at $1080^{\circ} \mathrm{C}$. In twostage deformation, the sample was firstly $30 \%$ compressed at $1080^{\circ} \mathrm{C}$, and then cooled at $2^{\circ} \mathrm{C} / \mathrm{s}$ to $850^{\circ} \mathrm{C}$ where $30 \%$ compression was performed again at a strain rate of $5 \mathrm{~s}^{-1}$. After hot deformation, the samples were cooled at $15^{\circ} \mathrm{C} / \mathrm{s}$ to $600^{\circ} \mathrm{C}$ and then slowly cooled at $0.5^{\circ} \mathrm{C} / \mathrm{s}$ to room temperature. The microstructures were characterized and the hardness was tested. In addition, to study ferrite transformation behaviors, several TZB steel samples were quenched during the slow cooling procedure in the one-stage deformation process. The samples were prepared and observed with optical microscope and SEM equipped with EBSD capability. Electron transparent foils for TEM were prepared using the conventional approach.

\section{Results and Discussion}

\subsection{CGHAZ Microstructures and Inclusions}

Figure 2 shows CGHAZs microstructures of TZ and A

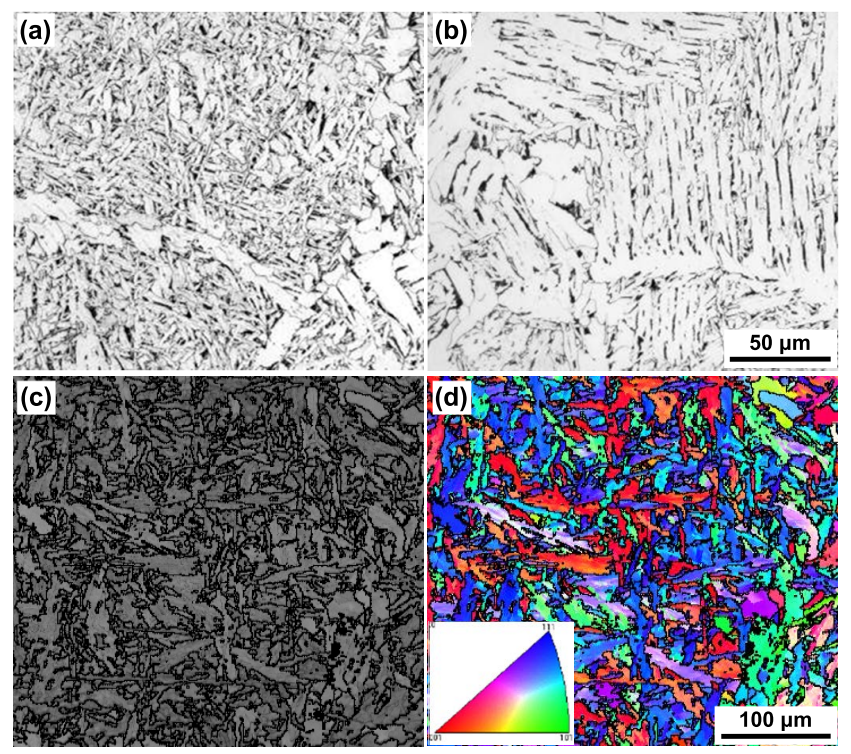

Fig. 2. (a, b) Optical microstructures of CGHAZs of $T Z$ steel and A steel respectively, (c, d) EBSD maps of CGHAZ of TZ steel. (Online version in color.)

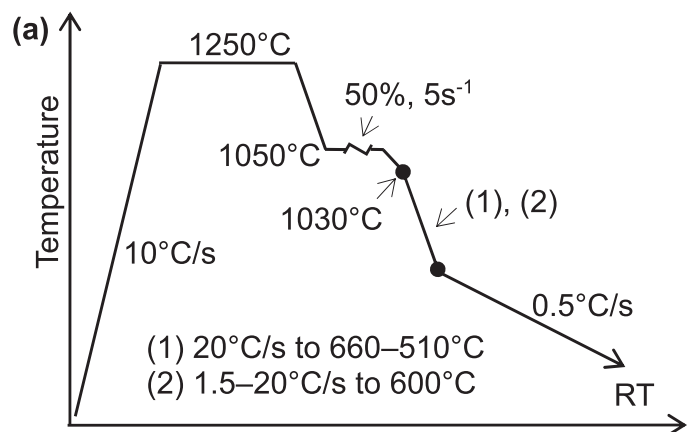

Time

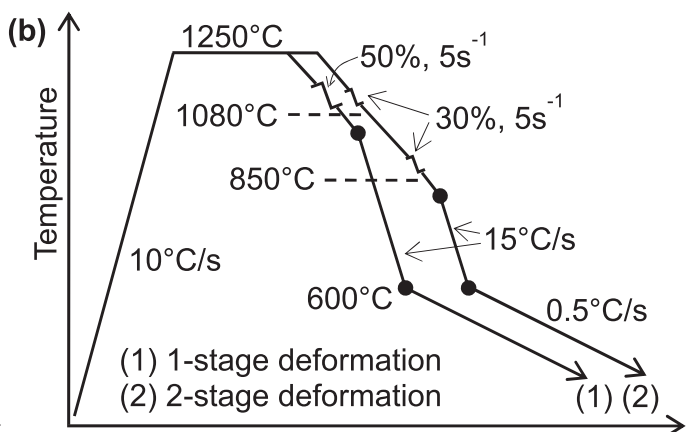

Time

Fig. 1. Schematic diagrams for simulating (a) controlled cooling and (b) hot rolling processes using thermo-mechanical simulator. 
steels with impact energy of $260 \mathrm{~J}$ and $20 \mathrm{~J}$ respectively. In TZ steel, as shown in Fig. 2(a), the microstructure consisted of grain boundary ferrite and intragranular acicular ferrite. In the A steel, coarse Widmanstätten ferrite and upper bainite were formed as shown in Fig. 2(b). Figures 2(c) and 2(d) show EBSD image-quality and grain orientation maps of TZ steel CGHAZ. The interlocking acicular ferrite plates were mainly related with high-angled grain boundaries. The effective grain size was significantly refined, which contributed to the high toughness. Crystallographic grain boundaries with misorientation angle $>15^{\circ}$ act as obstacles to crack propagation and increase the absorbed energy.

The intragranular AF nucleation in TZ steel CGHAZ was significantly promoted by $\mathrm{Ti}-\mathrm{Zr}$ deoxidization inclusions. An effective inclusion was scanned with EPMA and the result is shown in Fig. 3. Inclusions in $\mathrm{Ti}-\mathrm{Zr}$ killed steels are mainly complex type of $\mathrm{Ti}-\mathrm{Zr}-\mathrm{Al}-\mathrm{Mn}-\mathrm{O}+\mathrm{MnS}$. The oxide particles are rich in $\mathrm{Ti}$ and $\mathrm{Zr}$ and also contain trace $\mathrm{Al}$ and $\mathrm{Mn}$, with MnS precipitates on the surface. It could be simplified as $\mathrm{Ti}_{2} \mathrm{O}_{3} \cdot \mathrm{ZrO}_{2} \cdot \mathrm{MnS}$ for discussion. Most observed inclusions are less than $1 \mu \mathrm{m}$ in size. Oxygen content and total inclusion amount in Ti-Zr killed steels were controlled to be low in order to reduce the detrimental influence on toughness. The effectiveness of $\mathrm{Ti}_{2} \mathrm{O}_{3}$ is generally attributed to the formation of Mn-depletion zone (MDZ) through Mn atoms absorption into $\mathrm{Ti}_{2} \mathrm{O}_{3}$ or $\mathrm{MnS}$ adherent precipitation. ${ }^{9}{ }^{10)} \mathrm{ZrO}_{2}$ in the present steels was used mainly to refine inclusion size and promote $\mathrm{MnS}$ precipitation. Recent researches ${ }^{11,12)}$ indicated $\mathrm{ZrO}_{2}$ could also absorb $\mathrm{Mn}$ to form MDZ and induce ferrite nucleation. The non-metallic inclusions in Ti-Zr killed steels are expected to promote acicular ferrite formation in hot-rolled steel plates.

\subsection{Effect of Deformation Temperatures}

Microstructures of TZB steel deformed at different temperatures and that without deformation are shown in Fig. 4. Grain boundary ferrite, aligned ferrite plates and acicular ferrite existed in all samples with the difference in volume fractions. Distribution of grain boundary ferrite roughly indicated the prior austenite structure before transformation. In the steel without deformation, Fig. 4(a), large austenite grain size was obtained and acicular ferrite accounted for the most of microstructure. Austenite recrystallized and exhibited polygonal grains when deformation temperature was above $1000^{\circ} \mathrm{C}$, as indicated in Figs. 4(b)-4(e). The prior austenite grain size decreased with the decrease in deformation temperature and grain boundary ferrite content was thereby increased. However, acicular ferrite still

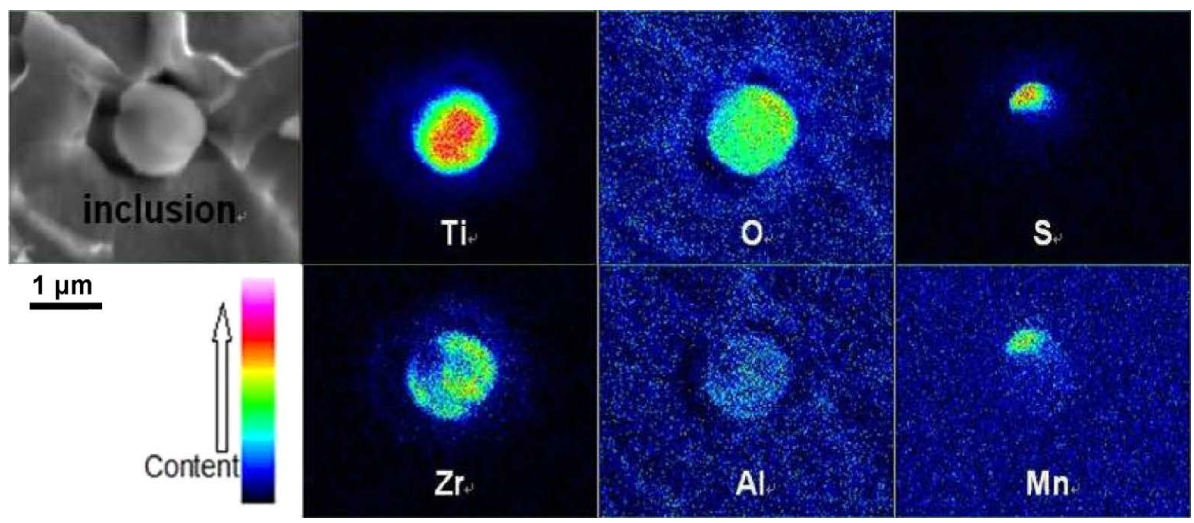

Fig. 3. Elements distribution maps of a nucleating inclusion in TZ steel by EPMA. (Online version in color.)

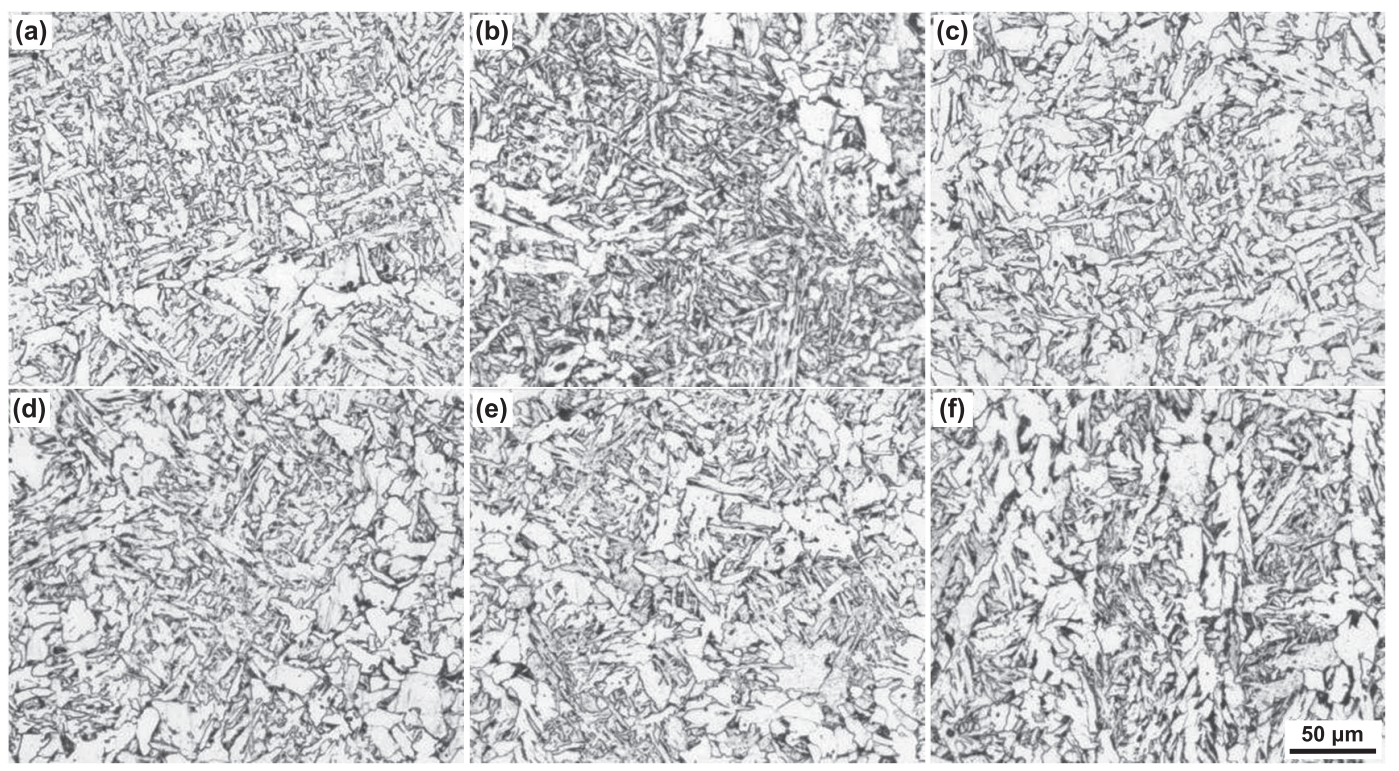

Fig. 4. Microstructures of TZB steel cooled at $2^{\circ} \mathrm{C} / \mathrm{s}$ after deformation at (a) no deformation, (b) $1150^{\circ} \mathrm{C}$, (c) $1100^{\circ} \mathrm{C}$, (d) $1050^{\circ} \mathrm{C}$, (e) $1000^{\circ} \mathrm{C}$, (f) $850^{\circ} \mathrm{C}$ 
made up the major part of microstructure with deformation at $1150-1050^{\circ} \mathrm{C}$ (Figs. 4(b)-4(d)), while the content of aligned ferrite plates increased when deformed at $1000^{\circ} \mathrm{C}$ (Fig. 4(e)). With deformation at $850^{\circ} \mathrm{C}$, austenite grains were pancaked to a certain extent and the AF content decreased notably, as indicated in Fig. 4(f). The fraction of intragranular ferrite including intragranular polygonal ferrite grains, acicular ferrite plates and packets, was determined as a function of deformation temperature with the result shown in Fig. 5. It seems that the rolling temperature should be above $1050^{\circ} \mathrm{C}$ in order to obtain a high $\mathrm{AF}$ fraction in hot-rolled steels.

Two conclusions could be obtained from the result: (i) inclusion-induced acicular ferrite nucleation was still valid in deformed and recrystallized austenite grains; (ii) acicular ferrite formation was discouraged by austenite deformation. Austenite recrystallization is a diffusional process as well as MDZ development. Deformation can lead to increase in crystalline defects such as dislocations, especially in the matrix around inclusions. The defects will act as diffusion pass and reduce the concentration gradient of Mn. Thus, Mn-depletion degree may be weakened and thereby its

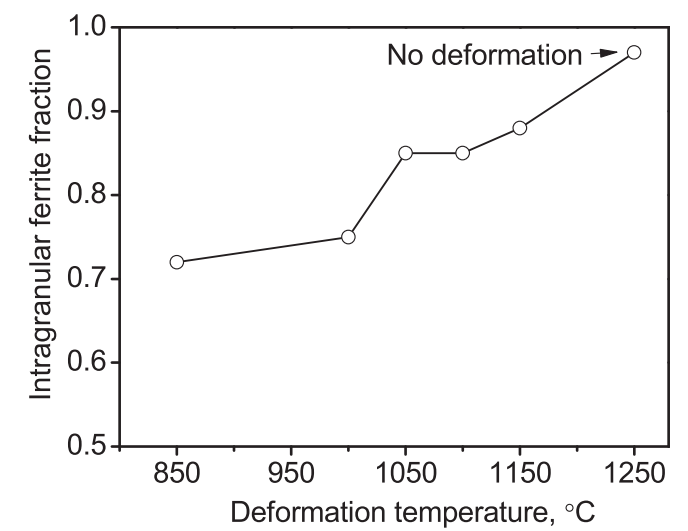

Fig. 5. Variation of intragranular ferrite fraction with deformation temperature. nucleating ability will be affected. However, at relatively high deformation temperatures, the Mn-depletion zones still remained and effectively induced ferrite nucleation. Furthermore, one main reason for the decrease in AF fraction was that austenite grain boundaries are more preferred nucleation sites for ferrite transformation. The grain surface area was increased by hot deformation and a larger amount of grain boundary ferrite formed consuming intragranular ferrite nucleating regions. ${ }^{5)}$

\subsection{Effect of Cooling Process}

Accelerated cooling process is of great importance in steel plate production. Microstructures and mechanical properties could be significantly improved through adopting controlled cooling process. In welding HAZ, the thermal cycle is fixed under given welding conditions, and the acicular ferrite formation could also be predictable. However, acicular ferrite formation in hot-rolled plates is expected to be optimized by controlling the cooling process in a feasible range for plate production. In this section, deformation temperature was selected as $1050^{\circ} \mathrm{C}$ in order to increase $\mathrm{AF}$ fraction. Following deformation, the samples were cooled at $20^{\circ} \mathrm{C} / \mathrm{s}$ to different temperatures and then slowly cooled at $0.5^{\circ} \mathrm{C} / \mathrm{s}$ to room temperature. The obtained microstructures of TZB steel are shown in Fig. 6. Microstructure for cooling stop temperature of $600^{\circ} \mathrm{C}$ is more refined than others, which is dominated by acicular ferrite, as shown in Fig. 6(c). When cooling stop temperature was $660^{\circ} \mathrm{C}$, almost fully polygonal ferrite formed. However, bainite packets largely formed with accelerated cooling to $540-510^{\circ} \mathrm{C}$. Microstructures with accelerated cooling stop temperatures of $630^{\circ} \mathrm{C}$ and $570^{\circ} \mathrm{C}$ exhibited transitive morphologies respectively. It was indicated that transformation mechanism for acicular ferrite is identical to bainite. ${ }^{13)}$ Acicular ferrite is essentially intragranularly nucleated bainite, whereas the conventional bainite plates are normally nucleated at austenite grain surface. Transformation temperature for acicular ferrite is raised due to MDZ formation. It was found that Mn deple-

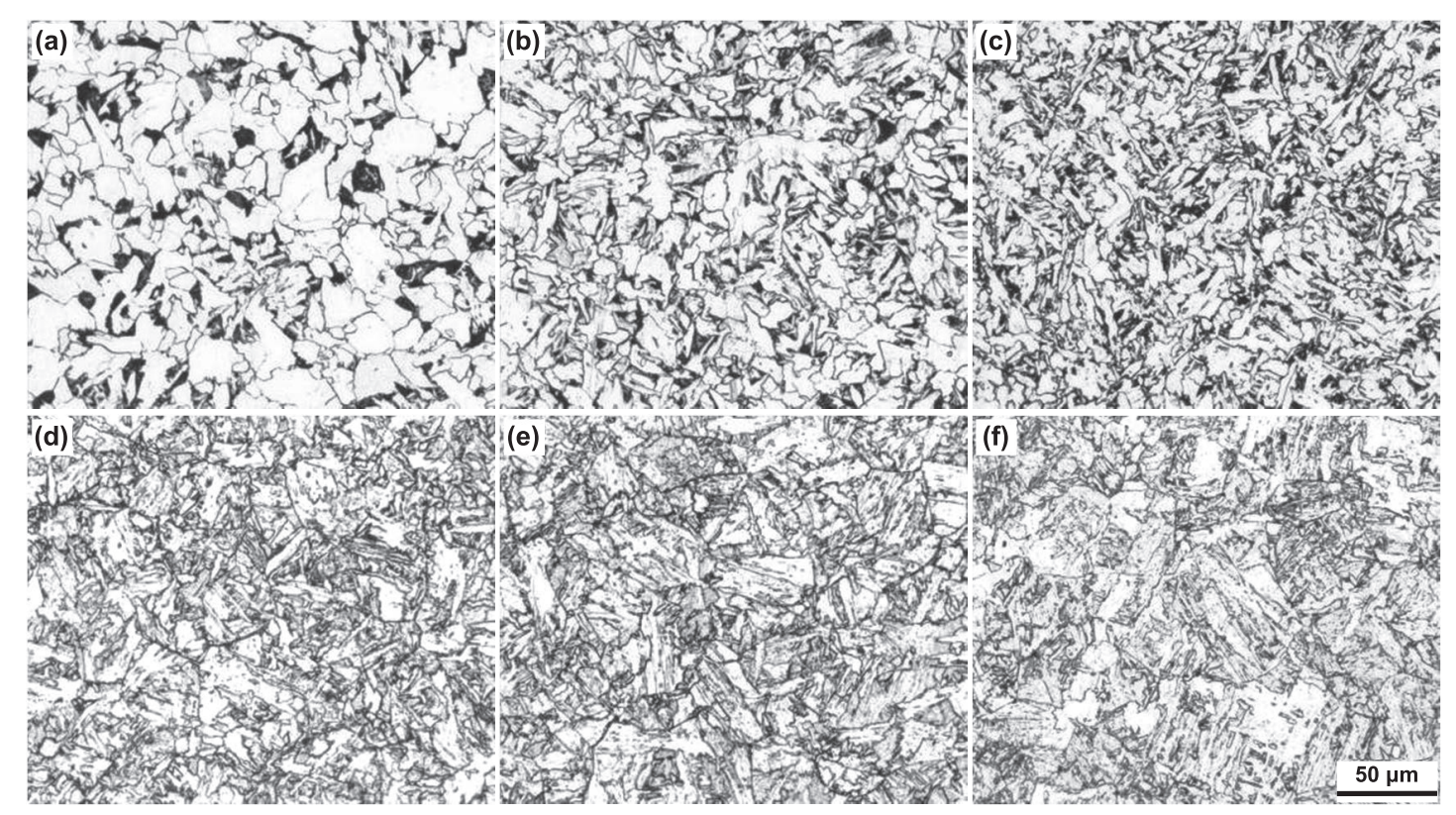

Fig. 6. Microstructures of TZB steel deformed at $1050^{\circ} \mathrm{C}$ and cooled at $20^{\circ} \mathrm{C} / \mathrm{s}$ to (a) $660^{\circ} \mathrm{C}$, (b) $630^{\circ} \mathrm{C}$, (c) $600^{\circ} \mathrm{C}$, (d) $570^{\circ} \mathrm{C}$, (e) $540^{\circ} \mathrm{C}$ and (f) $510^{\circ} \mathrm{C}$ followed by $0.5^{\circ} \mathrm{C} / \mathrm{s}$ cooling. 

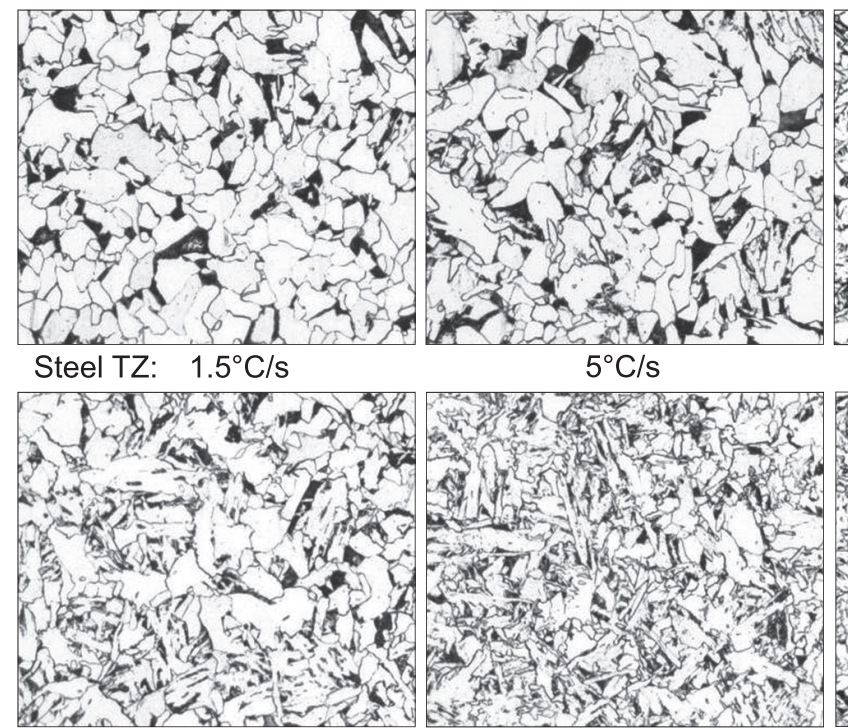

Steel TZB: $1.5^{\circ} \mathrm{C} / \mathrm{s}$

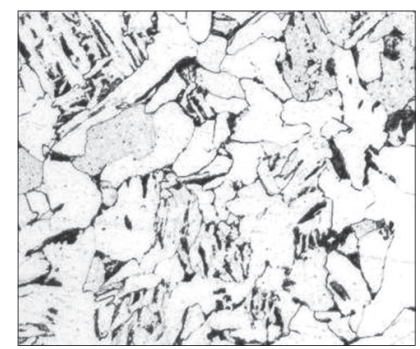

Steel A: $1.5^{\circ} \mathrm{C} / \mathrm{s}$ $5^{\circ} \mathrm{C} / \mathrm{s}$

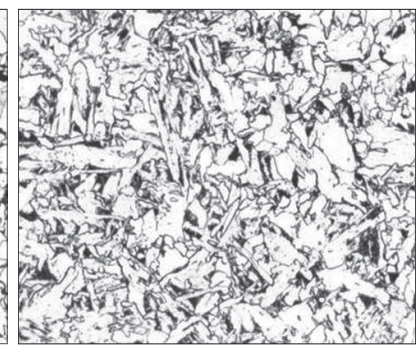

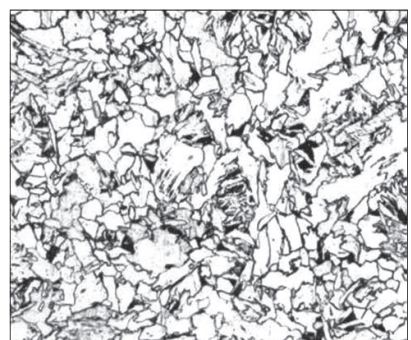

$10^{\circ} \mathrm{C} / \mathrm{s}$

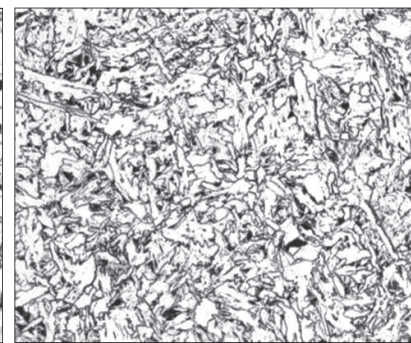

$10^{\circ} \mathrm{C} / \mathrm{s}$

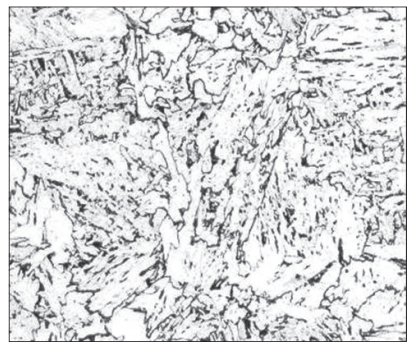

$10^{\circ} \mathrm{C} / \mathrm{s}$

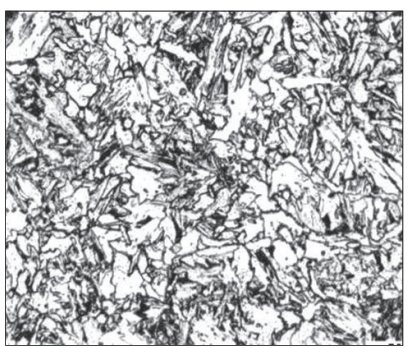

$20^{\circ} \mathrm{C} / \mathrm{s}$

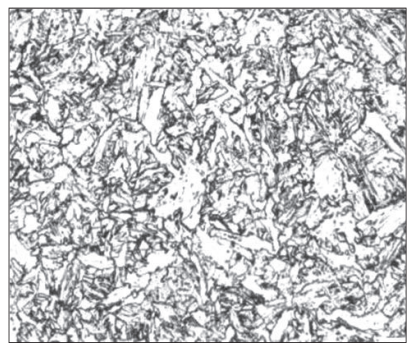

$20^{\circ} \mathrm{C} / \mathrm{s}$

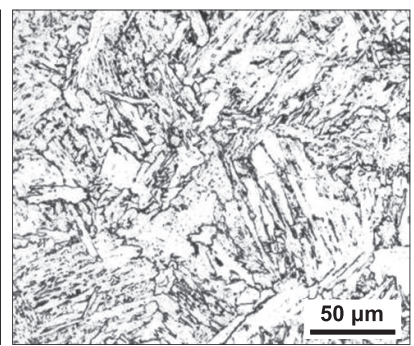

$20^{\circ} \mathrm{C} / \mathrm{s}$

Fig. 7. Microstructures of steels deformed at $1050^{\circ} \mathrm{C}$ and then cooled at different cooling rates of $1.5-20^{\circ} \mathrm{C} / \mathrm{s}$ to $600^{\circ} \mathrm{C}$ followed by $0.5^{\circ} \mathrm{C} / \mathrm{s}$ cooling.

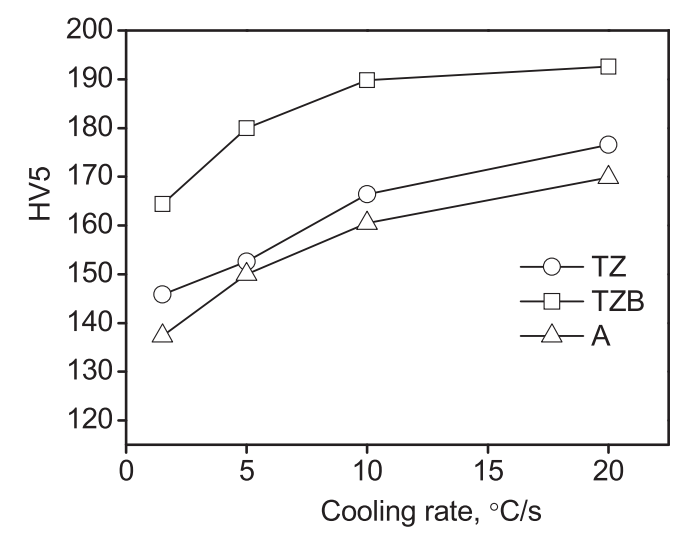

Fig. 8. Hardness of steel samples with different cooling rates.

tion of about $0.8 \%$ was made in MDZ area and transformation temperature from austenite to ferrite increased by about $30^{\circ} \mathrm{C}$. $^{9,14)}$ In the present TZB steel, acicular ferrite formed abundantly at about $600^{\circ} \mathrm{C}$. When temperature was lower than $570^{\circ} \mathrm{C}$, bainite transformation would acquire sufficient chemical driving force and the advantage in thermodynamics for acicular ferrite caused by MDZ became weak. Activation energy barrier for nucleation on grain boundaries is lower than intragranular inclusions so that transformation kinetics becomes more favorable for bainite than acicular ferrite. Coarse bainite sheaves obtained below $570^{\circ} \mathrm{C}$ would deteriorate the toughness of base metal. Thus, the accelerated cooling stop temperature should be controlled at about $600^{\circ} \mathrm{C}$ in order to promote acicular ferrite structure.

The temperature range from deformation to $600^{\circ} \mathrm{C}$ was designed for accelerated cooling. Microstructures with different accelerated cooling rates are shown in Fig. 7 as well as the corresponding hardness in Fig. 8. In TZ steel, polygonal ferrite was predominant with cooling rates up to $10^{\circ} \mathrm{C} / \mathrm{s}$. Acicular ferrite content increased significantly when the cooling rate increased to $20^{\circ} \mathrm{C} / \mathrm{s}$. However, microstructure and hardness of TZ steel for $20^{\circ} \mathrm{C} / \mathrm{s}$ just corresponds to that of TZB steel obtained with a cooling rate of $5^{\circ} \mathrm{C} / \mathrm{s}$. Acicular ferrite dominates the microstructures of TZB samples with cooling rates $>5^{\circ} \mathrm{C} / \mathrm{s}$. The results indicated that boron addition and increase in cooling rate significantly improved acicular ferrite formation and hardness. Boron addition in steel could retard the austenite-to-ferrite transformation due to its segregation at austenite grain boundaries during cooling. The retardation effect of $B$ is dependent on cooling rate. The predominant polygonal ferrite in TZB steel with $1.5^{\circ} \mathrm{C} / \mathrm{s}$ shows the weak effect of $\mathrm{B}$ at this cooling rate. However, the effect begins to be obvious at $5^{\circ} \mathrm{C} / \mathrm{s}$ and reaches the maximum at $10-20^{\circ} \mathrm{C} / \mathrm{s}$. This result agrees with the research of Mun et al. ${ }^{15)}$ It was indicated that the variation in retardation effect was related to the cooling rate-dependence of B segregation. $\mathrm{B}$ segregation mainly occurs by a non-equilibrium segregation mechanism and is strongly dependent on cooling rate. The segregation amount is very little at the cooling rate of $1^{\circ} \mathrm{C} / \mathrm{s}$ and increases with increasing cooling rate from 5 to $20^{\circ} \mathrm{C} / \mathrm{s} .{ }^{15)}$ Segregation of $\mathrm{B}$ at austenite grain boundaries suppresses the allotriomorphic ferrite nucleation, and however, B does not segregate on $\mathrm{Ti}_{2} \mathrm{O}_{3}$ surface due to its diffusion into $\mathrm{Ti}_{2} \mathrm{O}_{3} .{ }^{16)}$ Thus, the $\mathrm{AF}$ fraction was increased in TZB steel. Moreover, the effect of cooling rate on micro- 
structure and hardness of TZB steel appears less important when the cooling rate is above $10^{\circ} \mathrm{C} / \mathrm{s}$ because sufficient acicular ferrite content can be obtained at $10^{\circ} \mathrm{C} / \mathrm{s}$. The result suggests its usefulness for microstructural improvement of heavy steel products, in which coarse microstructure is usually formed because of high rolling temperature and slow cooling rate $<10^{\circ} \mathrm{C} / \mathrm{s}$. For these steels, by means of deoxidization and microalloying as the TZB steel, fine AF structure and high strength is expected to be obtained under cooling conditions of $5-10^{\circ} \mathrm{C} / \mathrm{s}$. For cooling rates $<5^{\circ} \mathrm{C} / \mathrm{s}$, alloying elements enhancing hardenability such as $\mathrm{Mn}$ and Mo can be increased to promote AF formation. ${ }^{17,18)}$ By comparison, microstructures in the A steel comprise coarse allotriomorphic ferrite and bainite sheaves growing from austenite grain boundaries, as shown in Fig. 7.

With the selected finish cooling temperature of $600^{\circ} \mathrm{C}$,

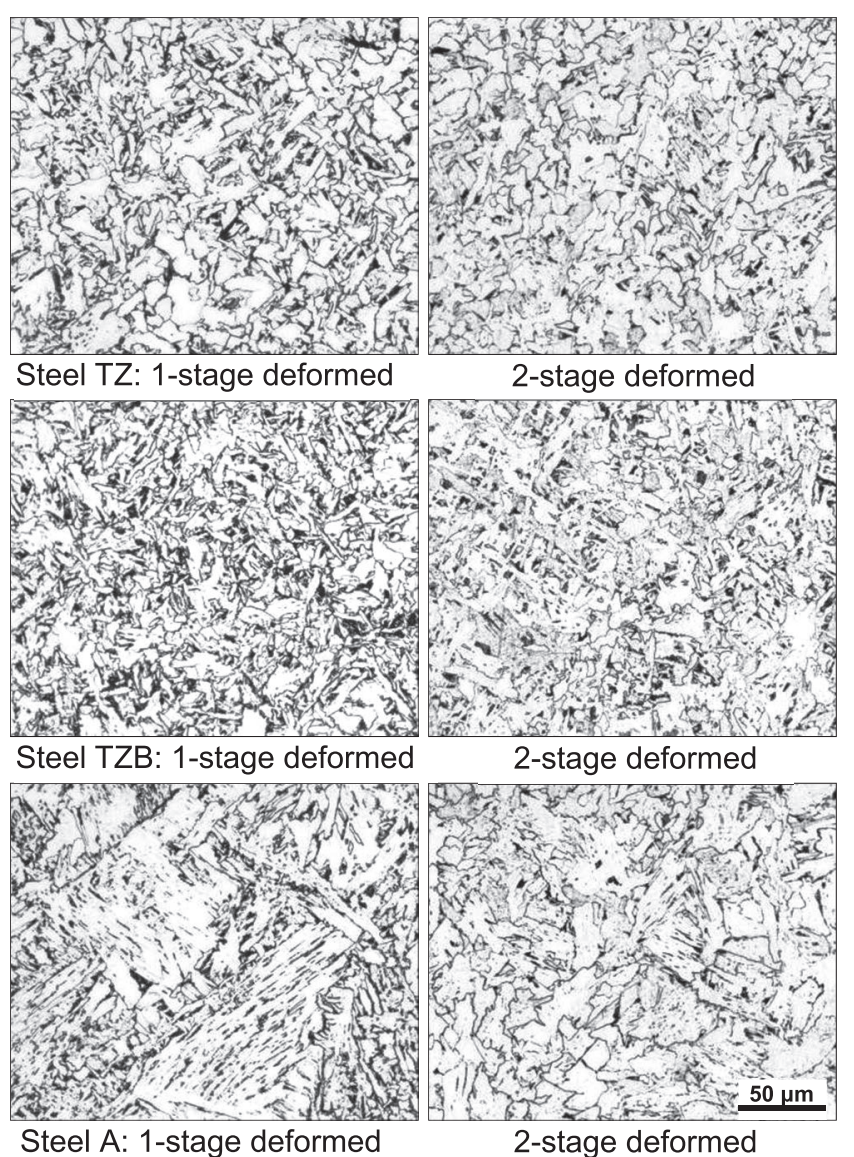

Fig. 9. As-simulated hot-rolled microstructures of steels with one-stage and two-stage deformation respectively. increase in cooling rate and addition of boron on one hand could prevent allotriomorphic ferrite from forming excessively and result in an increased residual austenite volume fraction for AF formation. On the other hand, a small amount of allotriomorphic ferrite could still form at relatively low temperatures, which would play a helpful role in developing acicular ferrite structure as follows. Allotriomorphic ferrite formation consumes the number density of austenite grain boundary nucleation sites for bainite formation. Moreover, allotriomorphic ferrite that forms at low temperatures could enrich the austenite ahead of ferrite/austenite interface with carbon element to a considerable extent such that start temperature for bainite or Widmanstätten ferrite growing from allotriomorphic ferrite becomes lower. ${ }^{19)}$ Thus, the acicular ferrite structure was further improved.

\subsection{Hot Rolling Simulation}

Hot rolling process was simulated via thermo-mechanical simulator with parameters referring to plate production practice and the above results. One-stage high temperature rolling and two-stage controlled rolling were both simulated. The microstructures and corresponding hardness are shown in Figs. 9 and 10. From Fig. 9 it was found that the effect of two-stage deformation on grain refinement was apparent for steel A, but seemed impotent for TZ and TZB steels. And besides, for $\mathrm{TZ}$ steel and especially for TZB steel, microstructures were able to be refined to a notable extent just with the one-stage high temperature deformation. It was attributed to the effective intragranular AF plate nucleation on $\mathrm{Ti}-\mathrm{Zr}$ oxide inclusions as indicated by Fig. 11(c). Two-stage deformation resulted in an increase in (quasi) polygonal ferrite fraction in TZ and TZB steels.

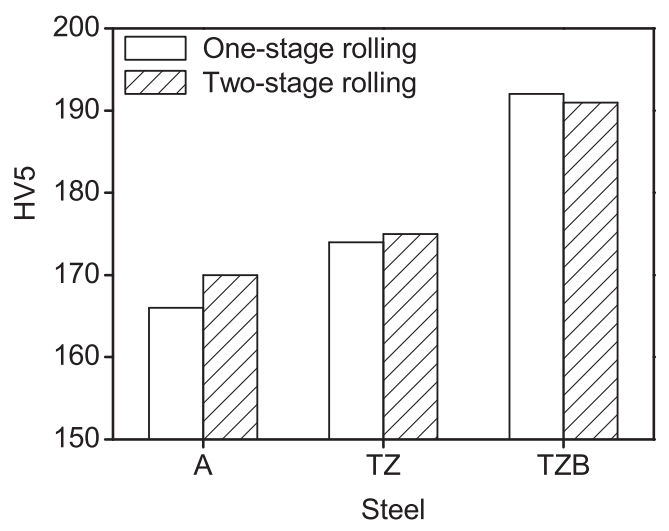

Fig. 10. Hardness of as-simulated hot-rolled steel samples.
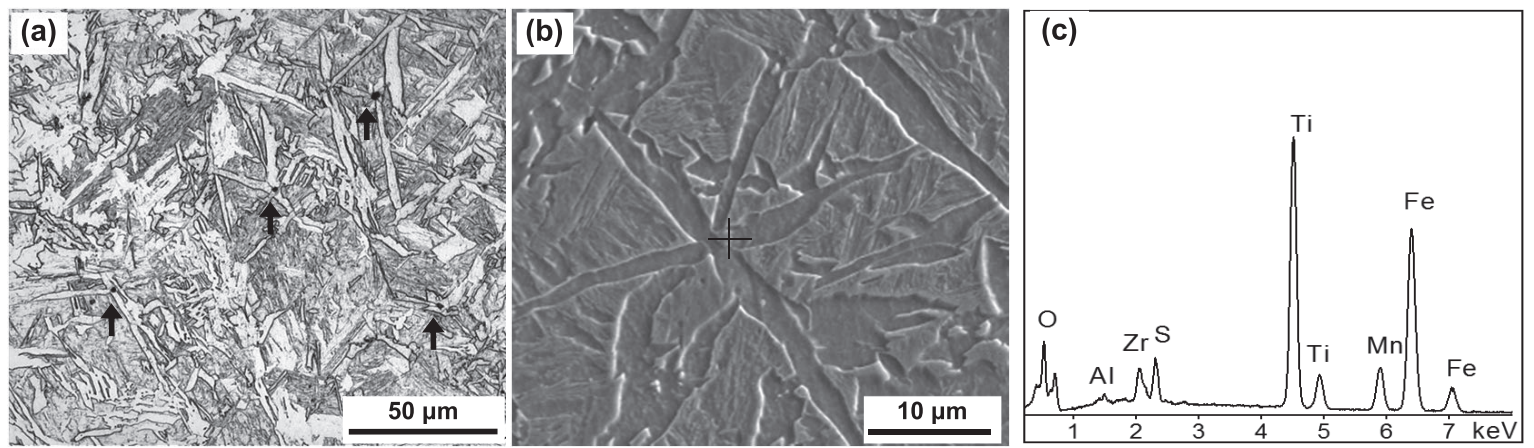

Fig. 11. (a) Optical and (b) SEM microstructures of TZB steel quenched from $596^{\circ} \mathrm{C}$, (c) EDS of the inclusion in (b). 
Bainite fraction also increased in TZB steel with a reduction of acicular ferrite. According to the hardness shown in Fig. 10, steel A received the grain refinement strengthening effect by two-stage deformation, whereas the hardness of TZB steel even exhibited some loss instead of further enhancement. Meanwhile, the hardness of TZB steel by one-stage deformation is significantly higher than others. It is expected that relatively high strength can be obtained by developing acicular ferrite microstructure for some heavy or long steel products, for which hot rolling should be finished at high temperature with limited pass reduction and conventional TMCP cannot be appropriately applied. In this sense, additionally, vanadium has been frequently used in hot-deformed steels to generate intragranular ferrite by $\mathrm{VN}$ or $\mathrm{V}(\mathrm{C}, \mathrm{N})$ precipitation. ${ }^{20-22)}$ In these steels to increase AF fraction, deformation at $850-950^{\circ} \mathrm{C}$ and adequate dwelling time after deformation as well as slow cooling before austenite decomposition seem necessary, during which $\mathrm{V}(\mathrm{C}, \mathrm{N})$ precipitation is promoted. ${ }^{21,22)}$

The result indicates that, for the present $\mathrm{Ti}-\mathrm{Zr}$ killed steel compositions, microstructures and hardness are not easy to be further improved by conventional controlled rolling process comparing with one-stage high temperature deformation. The main reason is that the decrease in austenite grain size caused by controlled rolling is unfavorable to inclusion-induced ferrite nucleation. The increase in austenite grain boundary area causes more allotriomorphic ferrite formation, as is especially the case in $\mathrm{TZ}$ steel. Moreover, the formation of bainite packets is favored with the increase of the ratio between grain boundary nucleating sites and intragranular inclusions. In addition, the effect of boron on suppressing grain boundary nucleation would also become weaker due to the less segregation at grain boundaries. ${ }^{23)}$ Research as regards producing acicular ferrite HSLA steels using residual oxide inclusions is limited. It is mainly because that HSLA steels are usually subjected to controlled rolling or TMCP treatment where the inclusions (the volume fraction is always low for the cleanness requirement) become nearly useless in grain refinement. On the other hand, acicular ferrite could be readily obtained in Nb-microalloyed TMCP steels such as linepipe steels. These steels are designed with heavy reduction in austenite non-recrystallization region and acicular ferrite is formed via nucleating at crystal defects within deformed austenite grains. $^{24-26)}$

It is noted that the acicular ferrite structure morphologies between one-stage deformed steel (TZB steel in Fig. 9) and CGHAZ (Fig. 2(a)) exhibit different characteristics. Acicular ferrite structure in CGHAZ is almost completely made up of individual AF plates in an interlocking arrangement. However, the as-rolled microstructure is evidently a combination of acicular ferrite (AF), (quasi) polygonal ferrite (QPF), granular or lath bainite $(\mathrm{GB} / \mathrm{LB})$ and microphase of carbide, (degenerated) pearlite (DP) or martensite/austenite (M/A) constituent. Microstructural details of as-simulated one-stage deformed TZB steel are shown in Fig. 12. Figure 12(d) also indicates a relatively high dislocation density in the matrix which contributes to the hardness. Microstructure as shown in Fig. 12(f) was observed with a very limited amount. The acicular ferrite plate was formed associated with elongated carbides distributing within the ferrite plate and along the plate boundary (respectively indicated by dot and dash lines). The interior carbides formed angles of about $50^{\circ}, 74^{\circ}$ or $17^{\circ}$ to the plate boundary. This kind of ferrite plate is referred to lower acicular ferrite corresponding to lower bainite. ${ }^{27,28)}$ Cementite carbides can precipitate from supersaturated ferrite and carbon-enriched austenite, presenting different spatial orientations respectively. ${ }^{28)}$ Lower acicular ferrite is considered to form only when carbon concentration is large enough to permit the precipitation of carbides from the acicular ferrite before much of the carbon can partition into the residual austenite. ${ }^{13)}$ Therefore lower acicular ferrite is not easy to form in low carbon steels. In the present steel, the seldom lower AF plate was supposed to be formed at a relatively low temperature during cooling, before which a large amount of ferrite was formed and ejected carbon into residual austenite to a sufficient extent. However, most ferrite plates in the present steel are cor-
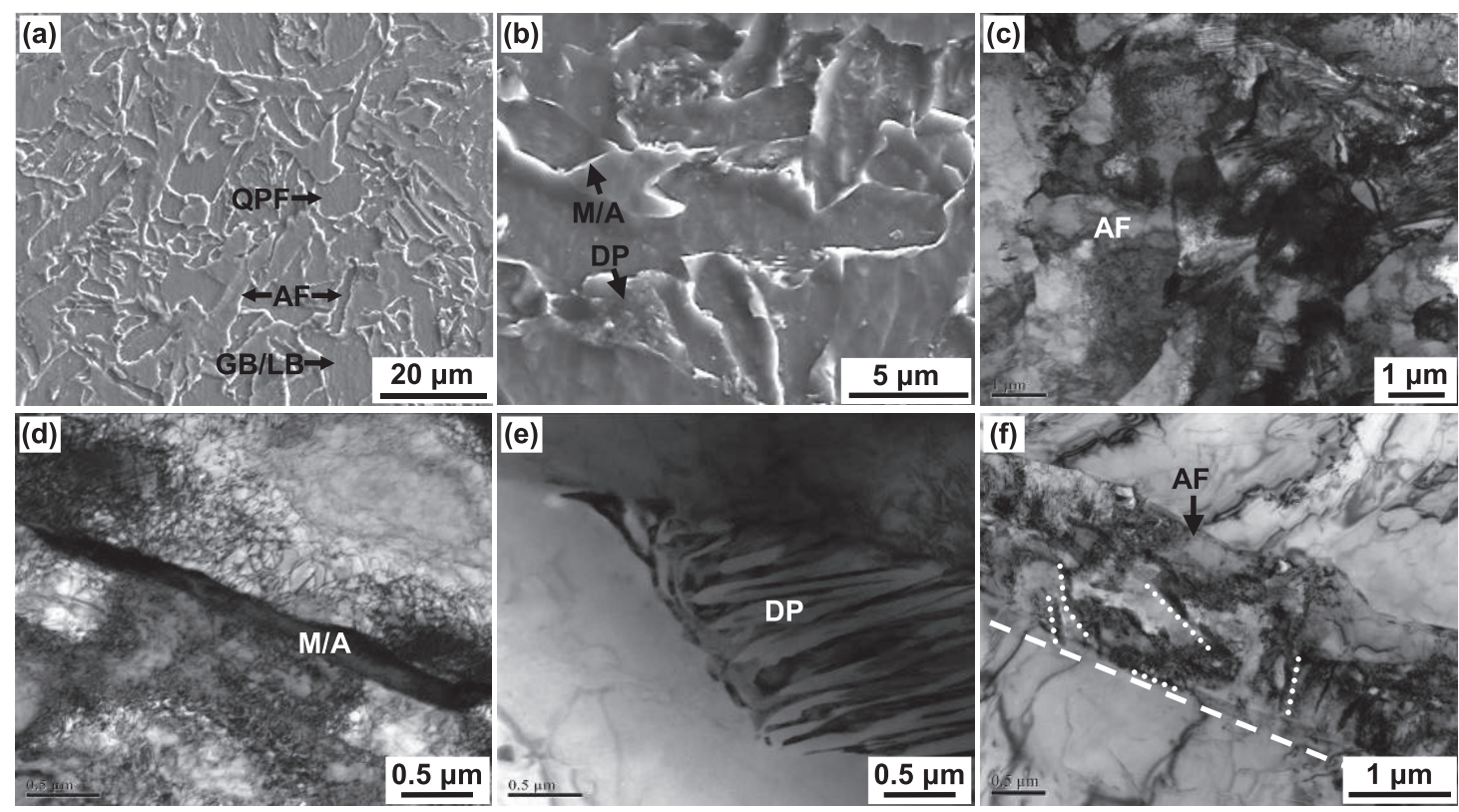

Fig. 12. (a, b) SEM and (c-f) TEM microstructures of TZB steel with simulated one-stage hot rolling. 
responding to upper acicular ferrite, with to some extent degenerated acicular shape and irregular boundaries due to coarsening of the plates. By comparison, the observed microstructure morphology in TZB steel is rather similar to that of linepipe steels in which acicular ferrite structure is used as a general term comprising multiple phases as are aforementioned. But microstructures in linepipe steels are more grain-refined because the profuse crystal defects within deformed austenite grains provide effective nucleating sites which are much higher in number than inclusion particles.

\section{Conclusions}

Effects of hot deformation and cooling process on the Ti-Zr killed low carbon steels were studied by thermomechanical simulation. Microstructural improvement by the aid of non-metallic inclusions in hot-rolled steels was evaluated. Main conclusions are as follows.

(1) Non-metallic inclusions in Ti-Zr killed steels are mainly ( $\mathrm{Ti}, \mathrm{Zr}$ )-rich oxide with $\mathrm{MnS}$ precipitation on the surface. The CGHAZ toughness was significantly improved through the inclusion-induced acicular ferrite microstructure.

(2) Acicular ferrite could still form in hot deformed and recrystallized austenite grains. However, the AF volume fraction reduced with the decrease in deformation temperature.

(3) Acicular ferrite of a high volume fraction was obtained in TZB steel when cooled at $20^{\circ} \mathrm{C} / \mathrm{s}$ to $600^{\circ} \mathrm{C}$. Accelerated cooling and addition of boron significantly promoted acicular ferrite structure and the hardness value also increased.

(4) Fine-grained acicular ferrite structure and high hardness was obtained through high temperature deformation and controlled cooling for the experimental $\mathrm{Ti}-\mathrm{Zr}-\mathrm{B}$ steel. ( $\mathrm{Ti}, \mathrm{Zr}$ )-oxide inclusions contributed to the intragranular acicular ferrite formation. Instead, the microstructure could not be further improved by applying conventional controlled rolling deformation.

\section{Acknowledgments}

This research was financially supported by the National Natural Science Foundation of China (No. 51234002) and the Fundamental Research Funds for the Central Universities of China (N140703001).

\section{REFERENCES}

1) T. Koseki and G. Thewlis: Mater. Sci. Technol., 21 (2005), 867.

2) D. S. Sarma, A. V. Karasev and P. G. Jonsson: ISIJ Int., 49 (2009), 1063.

3) K. F. A. Hajeri, C. I. Garcia, M. Hua and A. J. Deardo: ISIJ Int., 46 (2006), 1233.

4) J. S. Byun, J. H. Shim, J. Y. Suh, Y. J. Oh, Y. W. Cho, J. D. Shim and D. N. Lee: Mater. Sci. Eng. A, 319-321 (2001), 326.

5) J. H. Shim, J. S. Byun, Y. W. Cho, Y. J. Oh, J. D. Shim and D. N. Lee: ISIJ Int., 40 (2000), 819.

6) H. Tang, X. Chen, M. Chen, L. Zuo, B. Hou and Z. Wang: Mater. Sci. Eng. A, 609 (2014), 293.

7) F. Chai, C. F. Yang, H. Su, Y. Q. Zhang and Z. Xu: J. Iron Steel Res. Int., 16 (2009), 69.

8) H. Suito, A. V. Karasev, M. Hamada, R. Inoue and K. Nakajima: ISIJ Int., 51 (2011), 1151.

9) J. S. Byun, J. H. Shim, Y. W. Cho and D. N. Lee: Acta Mater., 51 (2003), 1593.

10) Y. B. Kang and H. G. Lee: ISIJ Int., 50 (2010), 501.

11) Y. Li, X. L. Wan, L. Cheng and K. M. Wu: Scr. Mater., 75 (2014), 78.

12) A. R. Dabiri, R. Y. Mojallal, E. Ahmadi, M. Fattahi, S. Amirkhanlou and Y. Fattahi: Mater. Lett., 158 (2015), 325.

13) H. K. D. H. Bhadeshia: Bainite in Steels, 2nd ed., Carlton House Terrace, London, (2001), 237.

14) K. Seo, Y. M. Kim, G. M. Evans, H. J. Kim and C. Lee: Weld. World, 59 (2015), 373.

15) D. J. Mun, E. J. Shin, Y. W. Choi, J. S. Lee and Y. M. Koo: Mater. Sci. Eng. A, $\mathbf{5 4 5}$ (2012), 214.

16) K. Yamamoto, T. Hasegawa and J. I. Takamura: ISIJ Int., 36 (1996), 80.

17) J. S. Byun, J. H. Shim and Y. W. Cho: Scr. Mater., 48 (2003), 449.

18) C. Capdevila, J. P. Ferrer, C. Garcia-Mateo, F. G. Caballero, V. Lopez and C. Garcia De Andres: ISIJ Int., 46 (2006), 1093.

19) S. S. Babu and H. K. D. H. Bhadeshia: Mater. Trans., 32 (1991), 679.

20) F. Ishikawa and T. Takahashi: ISIJ Int., 35 (1995), 1128.

21) S. F. Medina, M. Gomez and L. Rancel: Scr. Mater., 58 (2008), 1110.

22) C. Capdevila, C. Garcia-Mateo, J. Cornide, J. Chao and F. G. Caballero: Metall. Mater. Trans. A, 42A (2011), 3743.

23) D. Zhang, H. Terasaki and Y. I. Komizo: Acta Mater., 58 (2010), 1369.

24) Y. M. Kim, H. Lee and N. J. Kim: Mater. Sci. Eng. A, 478 (2008), 361.

25) B. Y. Zhang and J. D. Boyd: Metall. Mater. Trans. A, 41A (2010), 1448.

26) Z. Q. Cao, Y. P. Bao, Z. H. Xia, D. Luo, A. M. Guo and K. M. Wu: Int. J. Mineral. Metall. Mater., 17 (2010), 567.

27) A. A. B. Sugden and H. K. D. H. Bhadeshia: Metall. Trans. A, 20A (1989), 1811.

28) I. Madariaga, I. Gutierrez and H. K. D. H. Bhadeshia: Metall. Mater. Trans. A, 32A (2001), 2187. 